\title{
High Current Density PQQ-dependent Alcohol and Aldehyde
}

\section{Dehydrogenase Bioanodes}

\section{SIDNEY AQUINO NETO ${ }^{1,2}$, DAVID P. HICKEY ${ }^{2}$, ROSS D. MILTON ${ }^{2}$, ADALGISA R. DE ANDRADE ${ }^{1}$, SHELLEY D. MINTEER ${ }^{2 *}$}

1 Departamento de Química, Faculdade de Filosofia Ciências e Letras de Ribeirão Preto, Universidade de São Paulo, 14040-901, Ribeirão Preto, SP, Brazil

2 Departments of Chemistry and Materials Science and Engineering, University of Utah, Salt Lake City, Utah 84112 


\section{ABSTRACT}

In this paper, we explore the bioelectrooxidation of ethanol using pyrroloquinoline quinone (PQQ)-dependent alcohol and aldehyde dehydrogenase (ADH and AldDH) enzymes for biofuel cell applications. The bioanode architectures were designed with both direct electron transfer (DET) and mediated electron transfer (MET) mechanisms employing high surface area materials such as multi-walled carbon nanotubes (MWCNTs) and MWCNT-decorated gold nanoparticles, along with different immobilization techniques. Four different polymeric matrices were tested (tetrabutyl ammonium bromide (TBAB)-modified Nafion; octyl-modified linear polyethyleneimine $\left(\mathrm{C}_{8}\right.$-LPEI); and cellulose) in the DET studies. The modified Nafion membrane provided the best electrical communication between enzymes and the electrode surface, with catalytic currents as high as $16.8 \pm 2.1 \mu \mathrm{A} \mathrm{cm} \mathrm{cm}^{-2}$. Then, a series of ferrocene redox polymers were evaluated for MET. The redox polymer 1,1'-dimethylferrocene-modified linear polyethyleneimine $\left(\mathrm{FcMe}_{2}-\mathrm{C}_{3}\right.$ - LPEI) provided the best electrochemical response. Using this polymer, the electrochemical assays conducted in the presence of MWCNTs and MWCNTs-Au indicated a $J_{\max }$ of $781 \pm 59 \mu \mathrm{A} \mathrm{cm}{ }^{-2}$ and $925 \pm 68 \mu \mathrm{A} \mathrm{cm}{ }^{-2}$, respectively. Overall, from the results here obtained, DET using the PQQ-dependent $\mathrm{ADH}$ and AldDH still lacks high current density, while the bioanodes that operate via MET employing Fc-modified LPEI redox polymers show efficient energy conversion capability in ethanol/air biofuel cells.

KEYWORDS: PQQ-dependent Alcohol Dehydrogenase, PQQ-dependent Aldehyde Dehydrogenase, Direct Electron Transfer, Alcoholic Biofuel Cell, Ferrocene Mediators 


\section{Introduction}

Among the various alternative technologies for efficient energy conversion that have been developed over the past few decades, the use of enzymes immobilized onto the surface of electrodes as the main catalyst in biological fuel cells has been extensively reported (Aquino Neto and De Andrade 2013; Meredith and Minteer 2012; Rubenwolf et al. 2011). Operating at ambient temperatures and at near physiological $\mathrm{pH}$, these bioelectronic devices afford bioelectrocatalysis of a wide range of fuels (Sarma et al. 2009). Depending on the mechanism of electron transfer from the enzymes' active sites to the electrodes surfaces, bioelectronics are generally classified as direct electron transfer (DET) devices or mediated electron transfer (MET) devices. This general classification depends on the characteristics of the enzyme being used in each case. Even though more than one thousand enzymes that catalyze reactions involving electron transfer (oxidoreductase enzymes) are known, less than $10 \%$ of those are reported to be able to electrically connect to electrode surfaces by the DET mechanism (Ramanavicius and Ramanaviciene 2009). Therefore, most enzymatic biofuel cell studies rely on the use of a foreign redox species that can improve the electronic connection between the biological species and the electrical conductor, thus, increasing the electron transfer rates from the enzyme active sites and consequently the overall bioelectrochemical efficiency (Bullen et al. 2006). DET is generally due to the presence of metal-coordinated complexes within the protein structure (such as copper, iron, heme-c, etc.) near the surface of the enzyme(Falk et al. 2012), while MET studies typically focus on the use of ferrocene $(\mathrm{Fc})$, quinones, phenothiazine derivatives, and other metal complexes to relay electrons from the active sites, such as nicotinamide adenine dinucleotide (NAD) and flavin adenine dinucleotide (FAD), to electrode surfaces (Kavanagh and Leech 2013). 
A class of enzymes that are able to transfer electrons directly with electrode surfaces are hemoproteins. These enzymes have the characteristic iron containing heme groups $\left(\mathrm{Fe}^{+2}\right.$ in the center of a porphyrin ring), that display unique redox properties (Ramanavicius and Ramanaviciene 2009). In a similar fashion to NAD-dependent enzymes, quinohemoproteins (which have the cofactor PQQ as the redox center as well as heme-c's) are able to oxidize substrates and undergo DET with electrode surfaces (Ivnitski et al. 2007; Ramanavicius and Ramanaviciene 2009; Treu et al. 2009). Due to the bound PQQ cofactor and its tolerance to oxygen, these PQQ-dependent dehydrogenases are very convenient for the preparation of bioanodes for both biosensors and biofuel cells (Razumiene et al. 2006; Yuhashi et al. 2005). In this context, several PQQ-dependent dehydrogenase enzymes such as PQQ-dependent fructose, lactate, glycerol, alcohol and aldehyde dehydrogenase (PQQ-ADH and PQQAldDH) among others, have been isolated from bacteria such as Gluconobacter strains and explored in DET biofuel cell studies (Lapenaite et al. 2005; Schubart et al. 2012; Treu et al. 2009; Treu and Minteer 2008; Yuhashi et al. 2005). Despite the promising characteristics for DET and all of the advantages provided by this type of bioelectrode architecture for bioelectronic purposes, studies involving DET of PQQ-dependent enzymes still lacks high current densities, and for that reason, mediated electron transfer mechanism have also been exploited. The modification of carbon nanotubes with functional analogues of ubiquinone have shown to be a good alternative to provide a driving force for the electron transfer reaction of PQQ-dependent glucose dehydrogenase, generating high current densities (Babanova et al. 2014). Another proposed bioanode design to increase the generated current density employing the PQQdependent glucose dehydrogenase involved the use of a gold electrode modified with a PQQ-layer onto thiol-modified multi-walled carbon nanotubes (MWCNTs) (Tanne et 
al. 2010). Recently, quinone-modified MWCNTs were also investigated as a mediator in the bioelectrocatalytic oxidation of glucose employing the PQQ-dependent glucose dehydrogenase (Giroud et al. 2015). Considering the addition of mediators within bioanodes targeting alcohol oxidation, relevant literature has shown that the modification of screen-printed carbon electrodes with 4-(4ferrocenephenyliminomethyl)phenol provides improvement for ethanol sensing using the enzyme PQQ-ADH (Razumiene et al. 2003). In another example, a bioanode employing a recombinant PQQ-ADH has been designed based on the mediated electron transfer provided by aminoferrocene (Takeda et al. 2013).

In order to improve the electronic connection between enzymes and electrode surfaces, literature has focused on different strategies such as enzyme engineering, sitespecific interactions with the proteins, as well as the use of high surface materials in order to increase enzyme load and enhance the electronic signal (Babanova et al. 2014; Holland et al. 2011; Xu and Minteer 2013). Due to their biocompatibility and excellent electronic properties, materials such as MWCNTs and metallic nanoparticles are a good option for increased active surface area and improved bioanode performance (Wang et al. 2012). In previous investigations, we have devoted attention to the preparation of high surface area materials containing metallic nanoparticles and evaluated their behavior for alcoholic and sugar-based bioanodes (Aquino Neto et al. 2015a; Aquino Neto et al. 2014; Aquino Neto et al. 2015b). The results indicated that both the catalytic behavior and enhanced surface area provided by the metallic species account for better performance of these materials compared to the control electrodes. In this paper, we explore the bioelectrooxidation of ethanol through the use of the PQQ-dependent enzymes $\mathrm{ADH}$ and AldDH. The bioanode architectures were designed by either DET or MET mechanisms employing high surface area materials such as MWCNTs and 
MWCNTs-decorated gold nanoparticles, along with different immobilization techniques. Mediated electron transfer between enzymes and carbon electrodes was attempted using redox polymers based on ferrocene modified LPEI.

\section{Material and Methods}

\subsection{Chemicals}

Nafion ${ }^{\circledR} 1100$ EW 5\% by wt. suspension; Nafion ${ }^{\circledR}$ NRE212; Poly(amido amine) (PAMAM) dendrimers, ethylenediamine core, generation 4.0 solution; $\mathrm{HAuCl}_{4}$, microcrystalline cellulose and 1-ethyl-3-methylimidazolium acetate were purchased from Sigma-Aldrich and used as received. Ethyleneglycoldiglycidylether (EGDGE) was purchased from Polysciences Inc. Toray carbon paper electrodes and 20\% Pt gas diffusion electrodes were purchased from Fuel Cell Earth. MWCNTs (OD 20-30 nm, ID 5-10 nm, OL 10-30 $\mu \mathrm{m}$ ) were acquired from www.cheaptubes.com. Gluconobacter sp. 33 DSMZ 3504 was purchased from DSMZ (German Collection of Microorganisms and Cell Cultures). All the other reagents were of analytical grade and used without further purification. All solutions were prepared with high-purity water from a Millipore Milli$\mathrm{Q}$ system and $\mathrm{pH}$ measurements were carried out with a $\mathrm{pH}$ electrode coupled to a Fisher Scientific Accumet AB15+ Basic pH meter.

\subsection{Isolation and Purification of PQQ-ADH and PQQ-AldDH}

The PQQ-dependent enzymes ADH and AldDH were isolated and purified from Gluconobacter sp.33 (DSM 3504) (Treu et al. 2009). The aqueous basal media employed for bacterial cultivation was composed of $5 \mathrm{~g} \mathrm{~L}^{-1}$ of yeast extract, $1 \mathrm{~g} \mathrm{~L}^{-1}$ of $\left(\mathrm{NH}_{4}\right)_{2} \mathrm{HPO}_{4}, 2 \mathrm{~g} \mathrm{~L}^{-1}$ of $\mathrm{MgSO}_{4} \times 7 \mathrm{H}_{2} \mathrm{O}, 1 \mathrm{mM} \mathrm{CaCl}_{2}$, and mannitol $\left(10 \mathrm{~g} \mathrm{~L}^{-1}\right)$ was used as the carbon source. The $\mathrm{pH}$ of the media was then adjusted to 5.5 and sterilized. The 
commercial cells were firstly inoculated into $10 \mathrm{~mL}$ autoclaved media for starting culture growth. After saturation, the culture was transferred to a fermentation bottle containing $3 \mathrm{~L}$ of the same media. The cell growth was then carried out aerobically in a shaking incubator at $30{ }^{\circ} \mathrm{C}$ for about 24 hours. All subsequent steps were carried out at on ice bath or at $4^{\circ} \mathrm{C}$. After the growth, the cells were harvested via centrifugation $(5 \mathrm{~g}$ of cells are collected from $3 \mathrm{~L}$ media), washed with ice-cold $0.9 \% \mathrm{NaCl}$ solution, and then suspended in $20 \mathrm{~mL}$ of $0.2 \mathrm{~mol} \mathrm{~L}^{-1}$ Tris- $\mathrm{HCl}$ buffer $\mathrm{pH} 7.5$, containing $1 \mathrm{mmol} \mathrm{L}^{-1}$ $\mathrm{CaCl}_{2}$. After $1 \mathrm{~h}$ incubation in the presence of $0.5 \% \mathrm{CHAPS}, 20 \mathrm{mg}$ lysozyme, and 10 mg protease inhibitor, the cell lysis were carried out with the assistance of a microfluidizer (Microfluidics M-110P). After centrifugation of the crude lysate and a buffer exchange in $20 \mathrm{mmol} \mathrm{L}^{-1}$ tris- $\mathrm{HCl}$ buffer solution $\mathrm{pH} 7.5$ containing $1 \mathrm{mmol} \mathrm{L}^{-1}$ $\mathrm{CaCl}_{2}$ and $1 \%$ sucrose, the soluble fraction was applied to a weak anion exchange resin DEAE Toyopearl ${ }^{\circledR} 650 \mathrm{M}(2.5$ by $30 \mathrm{~cm})$ pre-equilibrated with the same buffer. The enzymes were eluted with the same buffer and active fractions were collected with a 75 mmol L ${ }^{-1}$ Tris- $\mathrm{HCl}$ buffer containing $1 \mathrm{mmol} \mathrm{L}^{-1} \mathrm{CaCl}_{2}, 1 \%$ sucrose, and $0.2 \%$ of Triton X-100. The active enzymes were then applied to a Toyopearl ${ }^{\circledR} \mathrm{CM}-650 \mathrm{M}$ cation exchange media and the PQQ-dependent enzymes ADH and AldDH are collected using a $20 \mathrm{mmol} \mathrm{L}{ }^{-1}$ Tris- $\mathrm{HCl}$ buffer solution $\mathrm{pH} 8$ containing $1 \mathrm{mmol} \mathrm{L}^{-1} \mathrm{CaCl}_{2}$, and 0.15 mol L $\mathrm{L}^{-1} \mathrm{NaCl}$. The final purified enzyme solution was then concentrated via Centriprep ${ }^{\circledR}$ $10 \mathrm{~K}$, and flash-frozen with liquid nitrogen in the presence of $10 \mathrm{mg} \mathrm{mL}^{-1}$ trehalose and $20 \mathrm{mg} \mathrm{mL}^{-1}$ polyethylene glycol.

The substrate oxidation activity of the purified enzyme solution or the immobilized proteins on carbon surfaces was assayed spectrophotometrically in the presence of the electron acceptors 2,6-dichlorophenol indophenol (DCIP) and phenazine methosulfate (PMS) using either ethanol or acetaldehyde as the substrate. The molar 
absorptivity coefficient determined for DCIP was $1.5510^{-4} \mathrm{~L} \mathrm{~mol}^{-1} \mathrm{~cm}^{-1}$ at $600 \mathrm{~nm}, \mathrm{pH}$ 7.5 in a UV/Visible Thermo Spectronic Genesys 20 Spectrophotometer. The absorbances were recorded for $2 \mathrm{~min}$, and the initial velocity was calculated by linear regression. Assays were performed in triplicate and controls without added enzyme were included in each experiment to quantify the non-enzymatic reaction of the substrate. One enzyme unit (U) is defined as the amount of enzyme that converts 1 $\mu \mathrm{mol}$ of substrate per minute per mg of protein.

\subsection{MWCNTs-decorated Au nanoparticle synthesis}

In our previous study, we investigated different synthetic protocols of $\mathrm{Au}$ nanoparticles supported on the surface of MWCNTs containing different functional groups. After evaluating their electrochemical responses in both alcohol and sugarbased bioanodes, the best response was achieved with the sample prepared with the Au nanoparticles synthesized by the dendrimer-encapsulated $\mathrm{Au}$ nanoparticle method, which was chosen for the current investigation (Aquino Neto et al. 2015a; Aquino Neto et al. 2014). As previously reported, the synthetic protocol involves a sequential twostep reaction, where first, the metallic species are stabilized onto the $\mathrm{NH}_{2}$-functionalized PAMAM dendrimers; after that, a strong reducing agent $\left(\mathrm{NaBH}_{4}\right)$ is added to achieve the encapsulated Au nanoparticles (Scott et al. 2004). Next, the encapsulated metallic nanoparticles are extracted from the dendrimer structure using a $20 \mathrm{mmol} \mathrm{L}^{-1} \mathrm{n}$ dodecanethiol solution in n-heptane, and finally, supported onto the surface of carbon nanotubes for a final $2 \mathrm{wt}$ \% metal catalyst loading, named MWCNTs-Au (Aquino Neto et al. 2015a). 


\subsection{Bioanode preparation}

\subsubsection{Bioanode in DET architecture}

The immobilization matrices used for DET studies were tetrabutyl ammonium bromide(TBAB)-modified Nafion, octyl-modified linear polyethyleneimine $\left(\mathrm{C}_{8}\right.$-LPEI), and cellulose entrapment. In the case of the enzyme immobilization procedure employing the TBAB-modified membrane, the bioelectrodes were prepared by immobilizing both PQQ-ADH and PQQ-AldDH enzymes onto carbon electrodes using a 5 wt. \% TBAB-modified-Nafion solution in ethanol, which was prepared as previously reported (Thomas et al. 2003). The hydrophobic modification of LPEI by an eight carbon chain was prepared as previously reported (Moehlenbrock et al. 2011). The entrapment of PQQ-ADH and PQQ-AldDH in cellulose was obtained by the modification of a previously reported procedure (Wu et al. 2009). Initially, cellulose $(3 \% \mathrm{w} / \mathrm{w})$ was dissolved and MWCNTs $(0.1 \% \mathrm{w} / \mathrm{w})$ were dispersed within EMIMacetate by sonication for approximately 2 minutes (using an ultrasonic horn), to yield EMIM-acetate/cellulose/MWCNTs. Before enzyme immobilization, $0.18 \mathrm{mg}$ of a MWCNTs (or MWCNT-Au) dispersion in isopropanol was pippeted onto the carbon surfaces and allowed to dry. Following, $6 \mu \mathrm{L}$ of an enzyme/polymer mixture was added to the $0.071 \mathrm{~cm}^{2}$ glassy carbon surface (which was previously polished and cleaned) or $40 \mu \mathrm{L}$ of the same solution were pippeted onto a $1 \mathrm{~cm}^{2}$ carbon paper platform. For TBAB-modified Nafion matrix, a 1:1 enzyme $10 \mathrm{mg} \mathrm{mL}^{-1}$ : TBAB-modified-Nafion ${ }^{\circledR}$ ratio was employed. For $\mathrm{C}_{8}$-LPEI matrix, a vortex-mixed solution containing $6.75 \mathrm{mg}$ $\mathrm{mL}^{-1} \mathrm{C}_{8}$-LPEI, $2.9 \mathrm{mg} \mathrm{mL}^{-1}$ purified PQQ-containing enzymes, and 0.15 vol \% EGDGE were employed. For enzymatic entrapment by cellulose, $6 \mu \mathrm{L}$ of the purified enzyme solution is first pippeted on top of the carbon electrodes, followed by the addition of 6 $\mu \mathrm{L}$ of the EMIM-acetate/cellulose/MWCNTs mixture. Next, the electrodes were 
inverted and placed within a vial containing DI water, resulting in the reconstitution of cellulose (embedded with MWCNTs) at the electrode surface; the ionic liquid can be recovered by distillation. The electrodes were then allowed to dry before use.

\subsubsection{Bioanode in MET architecture}

Two redox polymers based on ferrocene-modified LPEI provided the bioanode architecture for MET experiments. Previous studies conducted for the oxidation of glucose have shown that when complexed with glucose oxidase and cross-linked with EGDGE to form hydrogels, this material can provide an efficient driving force for shuttling electrons from the FAD active site to carbon surfaces with different redox potentials, depending on the characteristics of the ferrocene moieties (Meredith et al. 2011). LPEI modified with n-hexyl ferrocene $\left(\mathrm{Fc}-\mathrm{C}_{6}\right.$-LPEI) was prepared as previously reported (Meredith et al. 2011). For $\mathrm{FcMe}_{2}-\mathrm{C}_{3}$-LPEI preparation, LPEI was modified by the attachment of 3-(dimethylferrocenyl)propyl groups to $c a .17 \%$ of its nitrogen atoms $\left(\mathrm{FcMe}_{2}-\mathrm{C}_{3}\right.$-LPEI) (Meredith et al. 2011). For cyclic voltammetry experiments, the bioanode was prepared by pipetting $6 \mu \mathrm{L}$ of a vortex-mixed solution containing $6.75 \mathrm{mg}$ $\mathrm{mL}^{-1}$ of the redox polymer, $2.9 \mathrm{mg} \mathrm{mL}^{-1}$ purified PQQ-containing enzymes, and 0.15 vol \% EGDGE directly onto a $0.071 \mathrm{~cm}^{2}$ glassy carbon electrode surface, and gently dried under positive air-flow. The electrodes were then allowed to stand overnight, at room temperature. For the biofuel cell tests, the same methodology was employed, but in this case, the enzymes were immobilized onto a $1 \mathrm{~cm}^{2}$ Toray carbon paper platform using $40 \mu \mathrm{L}$ of the same solution containing the redox polymer and the cross-linker. In both situations, when prepared in the presence of MWCNTs (or MWCNTs-Au), 0.18 mg of a MWCNTs dispersion in isopropanol was added to the carbon surfaces and allowed to dry before the addition of the enzyme/mediator/cross-linker solution. 


\subsection{Instrumentation and electrochemical measurements}

Cyclic voltammetric and chronoamperometric electrochemical analyses were performed with a $\mathrm{CH}$ Instruments $611 \mathrm{C}$ potentiostat. The assays were conducted in a single compartment cell containing $0.2 \mathrm{M}$ Tris- $\mathrm{HCl}$ buffer $\mathrm{pH} 7.5$ and $1 \mathrm{mM} \mathrm{CaCl} 2$. Using a saturated calomel electrode (SCE) as the reference electrode and a platinum mesh as the counter electrode, cyclic voltammetry was performed at a scan rate of 10 $\mathrm{mV} \mathrm{s}^{-1}$. Chronoamperometric tests were conducted with consecutive additions of substrate at a fixed oxidative potential $(50 \mathrm{mV}$ larger than the oxidation peak potential). For power tests, current densities were measured in a compartmentalized cell in which a Nafion ${ }^{\circledR} 212$ proton exchange membrane was employed to separate the aqueous anodic chamber and the air-breathing $20 \%$ Pt gas diffusion electrodes cathode hot pressed to the membrane. The anodic cell compartment $(10 \mathrm{~mL})$ was filled $0.2 \mathrm{M}$ Tris- $\mathrm{HCl}$ buffer $\mathrm{pH} 7.5,1 \mathrm{mM} \mathrm{CaCl}_{2}$, and $0.02 \mathrm{~mol} \mathrm{~L}{ }^{-1}$ ethanol. The open circuit potential of the cell was measured for $1 \mathrm{~h}$, and quasi-stationary linear polarization was recorded at a scan rate of $1 \mathrm{mV} \mathrm{s}^{-1}$ from the open circuit potential to $0.001 \mathrm{~V}$. Power densities were calculated from the obtained data. All experiments were performed in triplicate and uncertainties correspond to one standard deviation. All electrochemical experiments were performed at room temperature $\left(22^{\circ} \mathrm{C}\right)$.

\section{RESULTS AND DISCUSSION}

Before the electrochemical characterization of the prepared bioanodes, kinetic activity tests were performed with the PQQ-dependent enzymes. The kinetic activity of the PQQ-dependent ADH and AldDH was determined in Tris buffer of $\mathrm{pH} 7.5$ to be $35.2 \pm 0.5 \mathrm{U} \mathrm{mg}^{-1}$ and $9.5 \pm 0.2 \mathrm{U} \mathrm{mg}^{-1}$ towards ethanol and acetaldehyde, respectively. 
Further, the obtained proteins fit the Michaelis-Menten model with a Michaelis constant $\left(K_{m}\right)$ of $0.14 \pm 0.08 \mathrm{mmol} \mathrm{L}^{-1}$ and $2.9 \pm 0.04 \mathrm{mmol} \mathrm{L}^{-1}$, respectively, for ethanol and acetaldehyde. Moreover, in order to verify the attachment of the enzymes onto the electrode surface, activity assays were also performed with both enzymes immobilized on glassy carbon surfaces along with the different polymeric matrices tested. The obtained data indicated quite similar behavior between the different materials employed, with enzymatic activity varying from $0.31 \pm 0.06$ to $0.62 \pm 0.11 \mathrm{U} \mathrm{mg}^{-1}$. The electrontransfer pathways of biocatalysis involving PQQ-dependent enzymes indicate that during the oxidation process, the substrate is first oxidized by the PQQ active site, and then an electron transfer process takes place through the heme-c moieties (Ikeda et al. 1993). Previous literature reports stated that during bioelectrocatalysis, ethanol or acetaldehyde delivers a pair of electrons to PQQ and the oxidized form of the cofactor is reduced to quinol $\left(\mathrm{PQQH}_{2}\right)$; then, one of these two electrons is transferred to the heme $\mathrm{c}$ moiety, leaving the PQQ in the semiquinone form (E. Ferapontova and Gorton 2005; Matsushita et al. 2002). Considering the addition of an electrode surface into this mechanism, we would expect that after substrate oxidation, electrons would be finally accepted by the electrical conductor either via the heme-c groups (through a oneelectron transfer mechanism), or direct via PQQ through a two-electron transfer mechanism (Figure 1A). Based on the presumed hydrophilic characteristics of PQQ, relevant literature reports that this group is most likely repelled away from the hydrophobic electrode surface, thus, favoring the one-electron transfer mechanism via the heme-c moiety (Ikeda et al. 1993). Based on this mechanism, another way to demonstrate the activity of the PQQ-dependent enzymes in the presence of a polymeric net is to perform a cyclic voltammetry experiment in a solution containing the same electron donors employed in the enzymatic activity assays. Figure $1 \mathrm{~B}$ reports a 
representative cyclic voltammetric experiment employing a bioanode containing both PQQ-dependent enzymes ADH and AldDH immobilized with TBAB-modified Nafion on a glassy carbon surface. The well-defined redox couple in the absence of substrate indicates good electrochemical communication between the enzymes and the electrode surface. The observed potential value is close to one of the heme-c moieties present in PQQ-dependent enzyme structure (Frébortova et al. 1998), indicating that this site must be responsible to transfer electrons to the electrode surface. Upon addition of ethanol, an increase in the redox peaks of both DCIP and PMS is observed, which indicates the functioning anode. The oxidation peak around $-0.10 \mathrm{~V} v s$. SCE and the reduction peak around $-0.13 \mathrm{~V}$ vs. SCE are related to DCIP, while the oxidation peak around $-0.22 \mathrm{~V}$ vs. SCE and the reduction peak around $-0.23 \mathrm{~V} v s$. SCE are related to PMS

Figure 1

\subsection{Electrochemical characterization of the bioanodes performing DET}

When immobilized in an appropriate orientation, the PQQ-dependent enzymes $\mathrm{ADH}$ and $\mathrm{AldDH}$ are able to oxidize substrates and transfer electrons to conducting surfaces without any kind of mediator species via a DET mechanism (Aquino Neto et al. 2013; Xu and Minteer 2013). In order to verify the ability of the purified enzymes to perform DET, cyclic voltammetry experiments were performed with the bioanodes prepared with different polymeric matrices, in the presence and in the absence of substrate. From the voltammetric behavior reported in Figure 2, we observed that all of the different polymeric matrices tested (TBAB-modified Nafion, $\mathrm{C}_{8}$-LPEI, and 
cellulose) were able to provide electrical communication between enzymes and the electrode surface. In fact, well-defined redox peaks, which are related to the heme-c moieties of the enzymes, were observed in all the performed assays. However, upon addition of substrate, not all electrode architectures were able to provide an environment for successful/efficient DET. Among the different immobilization methodologies tested, the modified Nafion membrane and the modified LPEI provided similar data, being the most efficient environment for DET, with a catalytic current density $\left(J_{\max }\right)$ of $16.8 \pm 2.1$

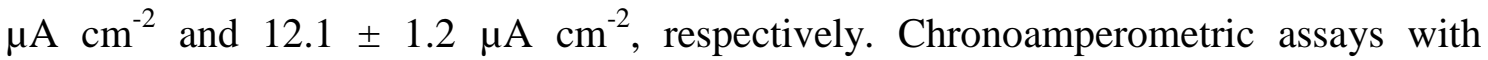
consecutive additions of substrate at a fixed potential $(0.050 \mathrm{~V}$ larger than the oxidation peak potential) further verified bioelectrocatalysis, where increasing concentrations of substrate lead to consecutive increases in catalytic current (inset of Figure 2A). In the case of the bioanode containing the PQQ-dependent enzymes entrapped within cellulose, the cyclic voltammograms registered in the absence or in the presence of substrate are quite similar; in fact, no statistically significant catalytic current is observed. In this type of system where the PQQ group acts mostly as the reactive site (whereas the heme-c moieties are the electron acceptor), it is quite important to consider the accessibility of these sites for substrate diffusion to the active site, as well as for electron transfer, so that efficient DET can be obtained. The modification of Nafion with TBAB increases the size of its micellar pore/pocket structure and provides stabilizing properties when immobilizing enzymes, while at the same time retaining good ion conductivity (Thomas et al. 2003). In the case of the modified LPEI (after crosslinking), the resulting enzymatic hydrogels are thought to provide sufficient proximity for the occurrence of electron transfer between the enzymes and electrode surface (Heller 1990; Moehlenbrock et al. 2011). Based on the aforementioned 
polymers characteristics, both diffusional and electronic transfers processes should be facilitated in these materials.

Figure 2

In order to increase the enzyme loading, electronic conductivity, and facilitate the electronic connection between enzymes and electrode surface, previous relevant literature has focused of the use of high surface area materials such as carbon nanotubes and metallic nanoparticles. Based on this premise, we have previously tested the use of Au nanoparticles supported on MWCNTs in enzymatic anodes, and our results indicate enhanced performance of this material compared to the unmodified nanotubes (Aquino Neto et al. 2015a; Aquino Neto et al. 2014; Aquino Neto et al. 2015b). In order to evaluate how the PQQ-dependent enzymes behave in the presence of the metallic species, hybrid bioanodes were prepared by immobilizing both PQQ-ADH and AldDH, along with the $\mathrm{Au}$ nanoparticle-modified nanotubes (MWCNTs-Au) and TBABmodified Nafion. Figure 3 reports the representative cyclic voltammograms obtained with the hybrid bioanode in the presence and absence of substrate, in which distinct electrochemical behavior is observed when compared to the data obtained with the regular MWCNTs in Figure 2. In fact, despite the increase in the catalytic oxidation current $\left(J_{\max }\right.$, of $\left.15.1 \pm 1.9 \mu \mathrm{A} \mathrm{cm}^{-2}\right)$, the obtained data also reports an increase in the reduction peak when in the presence of substrate. The most reasonable explanation to understand the electrochemical behavior obtained with the hybrid bioanode lies on the catalytic activity of the Au nanoparticles towards different organic substrates. In order to further explain the obtained data, electrochemical assays involving the different 
reduction reactions possibly occurring in the employed system were evaluated. In addition to evaluation of the enzymatic redox species heme-c and PQQ, cyclic voltammetry assays using the metallic catalyst only were performed with the substrate (ethanol) as well as with the products formed after enzymatic catalysis by the enzymes PQQ-ADH and AldDH, acetaldehyde and acetate (Gómez-Manzo et al. 2015). From the obtained data (not shown), no catalytic activity was observed for both heme-c and PQQ as well as for ethanol and acetaldehyde. Interestingly, the metallic species only displayed catalytic activity towards the reduction of acetate. Based on these tests, the observed increase in the reduction peak in Figure 3 can therefore be associated with the described reductive catalysis of acetate. Nevertheless, the enhancements in the catalytic currents that were thought to be provided by the presence of a higher surface area material containing the metallic species was not achieved in this assays, which is an indication that the bioelectrocatalysis of the proposed system is mainly limited by poor electronic communication between the enzymes' redox centers and the electrode surface, as well as the minor control of the enzyme arrangement for reaching efficient DET.

Figure 3

\subsection{Electrochemical characterization of the bioanodes performing MET}

Following the electrochemical characterization of the bioanodes performing DET and based on the low current densities generated in these bioanode configurations, we focused on the study of mediated systems employing the PQQ-dependent enzymes $\mathrm{ADH}$ and $\mathrm{AldDH}$ in an attempt to achieve high current density bioanodes. Literature 
has shown that ferrocene modified LPEI redox polymers are able to enhance electron shuttling between enzyme active sites and electrode surfaces as well as the stability of the bioelectrodes for sugar-based biofuel cells (Hickey et al. 2014; Meredith et al. 2013). Considering the use of ferrocene derivatives with PQQ-dependent ADH, modified screen-printed carbon electrodes containing 4-(4Ferrocenephenyliminomethyl)phenol and soluble aminoferrocene have also been explored in studies involving mediated electron transfer (Razumiene et al. 2003; Takeda et al. 2013).

In order to evaluate the ability of ferrocene molecules to mediate electron transfer from the enzymatic catalysis of ethanol using PQQ-dependent enzymes, preliminary tests using soluble ferrocene species were performed. Figure 4A presents representative cyclic voltammograms recorded in a solution containing $0.1 \mathrm{mg} \mathrm{mL} \mathrm{m}^{-1}$ ferrocenecarboxylic acid $(\mathrm{Fc}-\mathrm{COOH})$ and $20 \mathrm{mM}$ ethanol either in the absence or in the presence of the isolated enzymes. From the obtained data, it is clear that upon the addition of $10 \mu \mathrm{L}$ of the purified enzyme solution containing both PQQ-ADH and AldDH (giving final enzyme concentrations of $0.2 \mathrm{mg} \mathrm{mL}^{-1}$ ), an increase in the oxidation current as well as a decrease in the reduction peak is observed, confirming successful mediated electron transfer between PQQ-dependent enzymes and Fc-COOH molecules.

Figure 4

Following the successful mediation of the two PQQ enzymes by ferrocenecarboxylic acid, two redox polymers based on ferrocene modified LPEI were employed for bioanode preparation in order to yield immobilized proteins in the form of 
a redox hydrogel. The first step in the construction of the bioanodes is the optimization of the cross-linking reaction through the ratio of EGDGE and LPEI. In fact, the degree of cross-linking significantly affects the electron transport characteristics of the corresponding film. Further, substrate diffusion should be also affected under larger EGDGE concentrations, which could limit the $J_{\max }$ generated by the system (Hickey et al. 2014). In order to obtain higher catalytic currents and stability, assays were performed under varying crosslinker concentrations from 0.01 up to 1 vol $\%$ during bioanode preparation. The electrochemical data obtained indicates a significant influence from the amount of crosslinker employed and the final catalytic current as well as the physical stability of the prepared films. Figure $4 \mathrm{~B}$ and $4 \mathrm{C}$ report representative cyclic voltammograms recorded in the absence and in the presence of the substrate, with optimized bioanodes prepared with both $\mathrm{Fc}-\mathrm{C}_{6}$ - $\mathrm{LPEI}$ and $\mathrm{FcMe}_{2}-\mathrm{C}_{3^{-}}$ LPEI, respectively. In both cases, the electrochemical behavior obtained with the prepared bioanodes confirms catalytic behavior following the addition of substrate. While the assays employing both Fc and enzymes in solution obtained $J_{\max }$ values of 24 $\pm 2.0 \mu \mathrm{A} \mathrm{cm}{ }^{-2}$, the results achieved with enzymatic redox hydrogels demonstrate catalytic currents as high $20 \pm 1.8 \mu \mathrm{A} \mathrm{cm}{ }^{-2}$ with $\mathrm{Fc}_{-} \mathrm{C}_{6}$-LPEI and $350 \pm 18 \mu \mathrm{A} \mathrm{cm}{ }^{-2}$ when using $\mathrm{FcMe}_{2}-\mathrm{C}_{3}$-LPEI as the redox polymer hydrogel. From the data obtained, the $0.120 \mathrm{~V} v s$. SCE shift in the oxidation potential provided by the $\mathrm{FcMe}_{2}-\mathrm{C}_{3}$-LPEI redox polymer (compared to either ferrocenecarboxylic acid or $\mathrm{Fc}_{-} \mathrm{C}_{6}$-LPEI) largely accounts for the significantly improved catalytic currents achieved with this polymer (also, literature has shown that methylated ferrocene display enhanced electrochemical stability (Meredith et al. 2011)). A potential difference of around $50 \mathrm{mV}$ has been proposed to provide the optimal performance between enzymes and redox mediators (Heller 2004). In fact, considering the low redox potentials involved in the PQQ- 
dependent enzymes structure, the use of $\mathrm{FcMe}_{2}-\mathrm{C}_{3}$-LPEI with an $E_{1 / 2}$ (estimated by $\left(E_{p a}\right.$ $\left.\left.+E_{p c}\right) / 2\right)$ ) of $+0.18 \mathrm{~V} v s$. SCE allows for a more efficient shuttling of electrons between enzymes redox center and electrode surface. Moreover, when compared with the results achieved with the mediator in solution, the enhanced electron transfer process between enzymes and electrode surfaces obtained with the immobilized proteins is most likely due to the resulting three-dimensional network in which the enzymes and the redox polymer are immobilized. Following crosslinking of the polymer/enzyme structure, the enzymes' redox sites are thought to be in close proximity with the ferrocene redox moieties, which results in efficient electron transfer to the electrode surface. Further, the redox hydrogel allows a higher enzyme loading and more efficient electrical communication with the ferrocene species, which results in larger current densities.

In order to increase the current densities generated by the enzymatic systems, we also conducted the bioanode preparation in the presence of high surface materials. Figure 5A reports representative cyclic voltammograms obtained with the bioanodes prepared with the $\mathrm{FcMe}_{2}-\mathrm{C}_{3}$-LPEI redox polymer in the presence of either MWCNTs or $\mathrm{Au}$ nanoparticle-decorated MWCNTs. From the obtained voltammetric data, we observed that the presence of the carbon nanotubes and the hybrid material containing Au nanoparticles improved bioanode performance. In the first case, a $J_{\max }$ of $781 \pm 59$ $\mu \mathrm{A} \mathrm{cm}^{-2}$ was obtained while the hybrid material was capable of generating $925 \pm 68 \mu \mathrm{A}$ $\mathrm{cm}^{-2}$. As expected, the increased surface area provided by the employed nanomaterials improved bioanode performance. By comparison of this data with that observed in the electrochemical characterization employing the bioanode prepared with the redox polymer and enzymes only, a 2.2 and a 2.6 -fold increase in catalytic current was obtained for each composite electrode, respectively. Moreover, considering the enhanced performance achieved with the hybrid material containing Au nanoparticles 
we have previously observed similar data, in which the presence of the metallic species within the bioanode structure enhances the bioanode performance (Aquino Neto et al. 2015b). Factors such as larger surface area and higher electronic conductivity at the electrode surface indeed can improve the electron transfer processes; furthermore, the presence of the metallic species may also result in higher enzyme loadings and consequently improved bioanode performance. In order to further visualize the bioelectrocatalysis of ethanol in the prepared system, chronoamperometric studies were undertaken at a fixed oxidation potential $(0.05 \mathrm{~V}$ larger than the oxidation peak potential) by gradually increasing the concentration of substrate in the electrolyte solution. Figure 5B presents a representative chronoamperometric assay performed with a bioanode prepared with the $\mathrm{FcMe}_{2}-\mathrm{C}_{3}$-LPEI redox polymer in the presence of MWCNTs-Au nanoparticles. From the data obtained, we can clearly visualize that increased additions of substrate lead to consecutive increases in $J_{\max }$; further, a largely linear response is observed up to $10 \mathrm{mM}$ ethanol, followed by a plateau up to saturation at $20 \mathrm{mM}$ ethanol.

Figure 5

Following the electrochemical characterization using cyclic voltammetry and the chronoamperometry assays, we also conducted fuel cell polarization tests with the prepared bioanodes using an air-breathing $20 \% \mathrm{Pt}$ gas diffusion electrode as the cathode material (Figure 6). From the data obtained, the same electrochemical behavior observed in the cyclic voltammetry characterization is reproduced in the biofuel cell tests, in which enhanced performance is achieved for the nanostructured bioanodes prepared with the $\mathrm{FcMe}_{2}-\mathrm{C}_{3}$-LPEI redox polymer in the presence of either MWCNTs or 
MWCNT-decorated Au nanoparticles. For the bioanodes prepared with the redox polymer and enzymes only, an open circuit potential of $608 \pm 23 \mathrm{mV}$ and maximum current and power density of respectively $335 \pm 40 \mu \mathrm{A} \mathrm{cm}^{-2}$ and $90 \pm 11 \mu \mathrm{W} \mathrm{cm}{ }^{-2}$ were achieved. For the bioanodes prepared in the presence of MWCNTs, the obtained open circuit potential was of $614 \pm 25 \mathrm{mV}$, while $877 \pm 88 \mu \mathrm{A} \mathrm{cm}^{-2}$ and $198 \pm 20 \mu \mathrm{W} \mathrm{cm}{ }^{-2}$ were respectively the maximum current and power density. Finally, in the biofuel cell tests employing the hybrid bioelectrode containing MWCNTs-Au, an open circuit potential of $620 \pm 25 \mathrm{mV}$ and maximum current and power density of respectively 993 $\pm 114 \mu \mathrm{A} \mathrm{cm}^{-2}$ and $280 \pm 35 \mu \mathrm{W} \mathrm{cm}{ }^{-2}$ were achieved.

Figure 6

\section{Conclusions}

From the different polymeric matrices tested (TBAB-modified Nafion, $\mathrm{C}_{8}$-LPEI, and cellulose) in an attempt to immobilize the PQQ-dependent ADH and AldDH while promoting DET, well-defined redox peaks were observed in all of the performed assays. However, upon addition of substrate, catalytic currents were only observed with the TBAB-modified Nafion and the modified LPEI, wherein the modified Nafion membrane provided the best electrical communication between enzymes and the electrode surface with catalytic currents as high as $16.8 \pm 2.1 \mu \mathrm{A} \mathrm{cm}^{-2}$. Electrochemical assays with bioanodes prepared in the presence of MWCNTs-Au showed no significant improvement in catalytic current, indicating that the bioelectrocatalysis of the proposed system is mainly limited by poor electronic communication between the enzymes' 
redox centers and electrode surface, as well as poor enzyme orientation required for efficient DET. From the two redox polymers based on ferrocene-modified LPEI employed for bioanode preparation in the MET architecture, $\mathrm{FcMe}_{2}-\mathrm{C}_{3}$ - $\mathrm{LPEI}$ allows for improved shuttling of electrons between the enzymes' redox centers and electrode surface. In fact, the $120 \mathrm{mV}$ vs. SCE shift in the oxidation potential provided by the $\mathrm{FcMe}_{2}-\mathrm{C}_{3}$-LPEI redox polymer (compared to either ferrocenecarboxylic acid or $\mathrm{Fc}_{-}-\mathrm{C}_{6}$ LPEI) accounts for significantly higher catalytic currents achieved with this polymer $\left(350 \pm 18 \mu \mathrm{A} \mathrm{cm}^{-2}\right)$. From the electrochemical assays conducted on high surface area materials, we observed that the presence of both MWCNT and MWCNTs-Au improves bioanode performance. In the first case, a $J_{\max }$ of $781 \pm 59 \mu \mathrm{A} \mathrm{cm} \mathrm{cm}^{-2}$ was obtained, while the hybrid material was capable of generating $925 \pm 68 \mu \mathrm{A} \mathrm{cm}$. The results of this study demonstrate the improved performance of these PQQ enzymes via an MET mechanism over that of a DET mechanism, indicating improved energy conversion capabilities. 


\section{AUTHOR INFORMATION}

\section{Corresponding Author}

*E-mail: minteer@chem.utah.edu. Phone: (801) 587-8325.

\section{Notes}

The authors declare no competing financial interest.

\section{ACKNOWLEDGMENTS}

Financial support from FAPESP (Grant 2012/10667-0 and 2014/00536-0), CAPES, and CNPq are gratefully acknowledged. The authors also thank the National Science Foundation (Grant \# 1158943). The authors would also like to thank Emily Suda de Aquino for isolation and purification of the PQQ-dependent enzymes. 


\section{FIGURES}

Fig. 1.
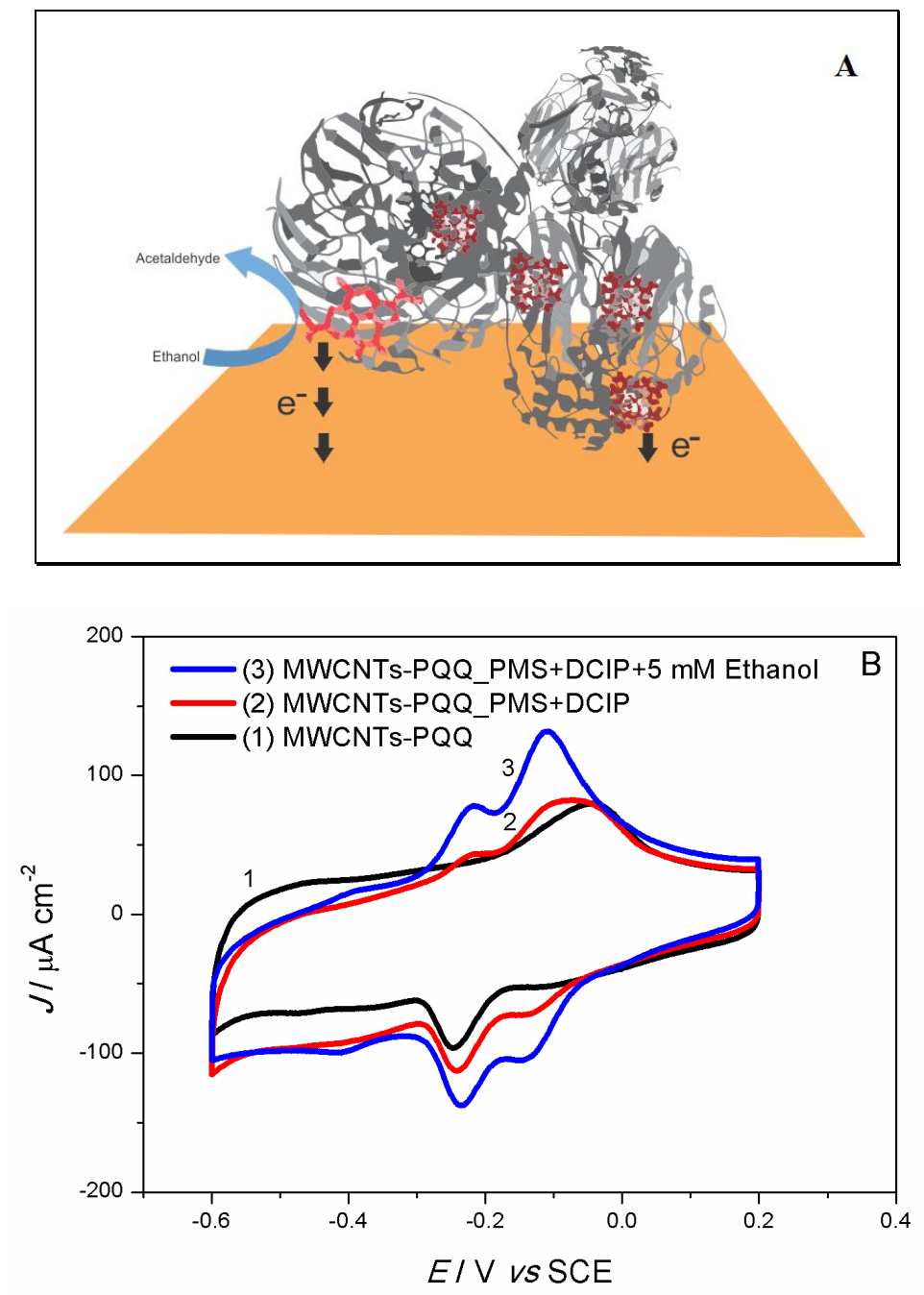

Figure 1. (A) Representative scheme of the electron transfer process between PQQ-dependent enzyme ADH and electrode surface via heme-c groups (on the right), or direct via the PQQ active site (on the left). The PQQ active site is represented in red and the four heme-c groups in dark red. (B) Representative cyclic voltammograms with a bioanode containing both PQQ-dependent enzymes ADH and AldDH immobilized with TBAB-modified Nafion on a glassy carbon surface in the presence of the electron acceptors DCIP, PMS, and $5 \mathrm{mM}$ ethanol, $\mathrm{pH} 7.5$ at $0.010 \mathrm{~V} \mathrm{~s}^{-1}$. 
Fig. 2.
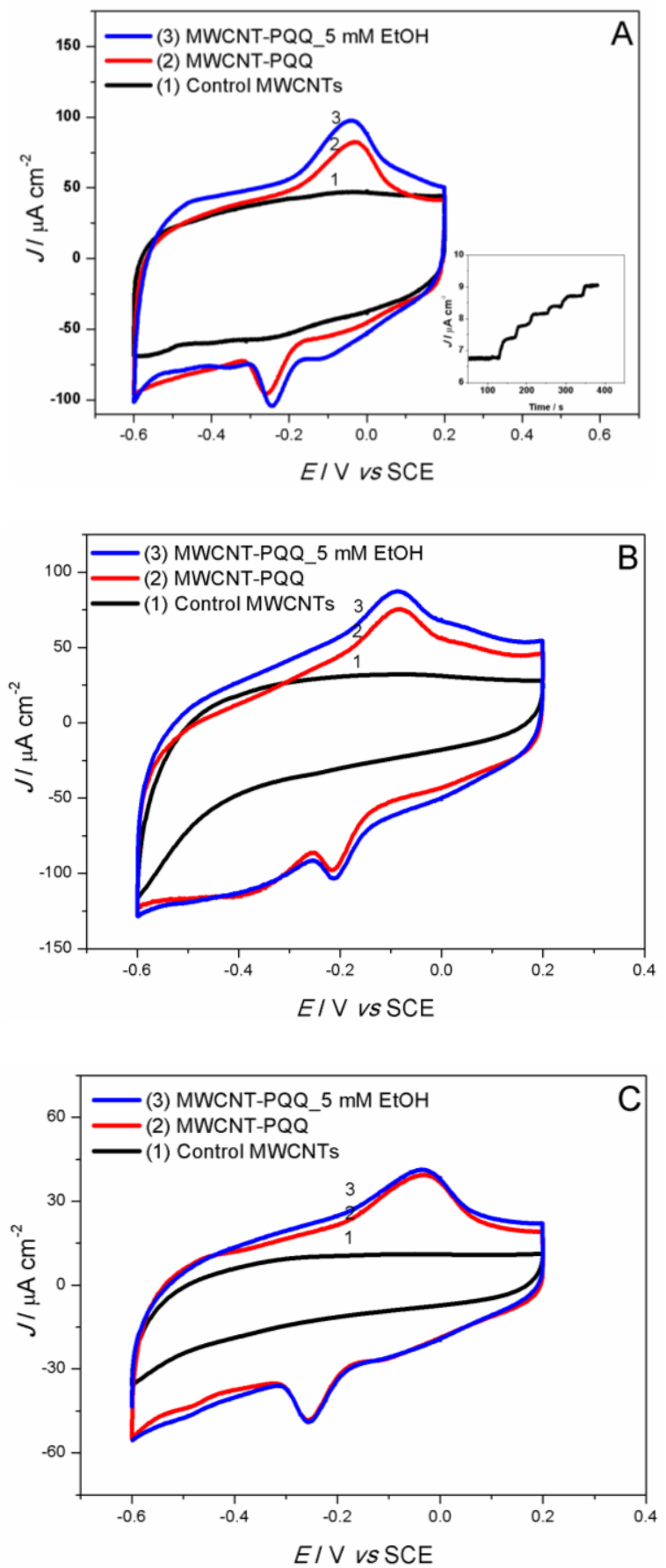

Figure 2. Representative cyclic voltammograms of the bioanodes containing both PQQ-dependent enzymes (ADH and AldDH) in DET architectures employing different polymeric matrices for enzyme immobilization. (A) TBAB-modified Nafion ${ }^{\circledR}$; (B) $\mathrm{C}_{8}$-LPEI; (C) Cellulose; in $0.2 \mathrm{~mol} \mathrm{~L}^{-1}$ tris ${ }^{+}$buffer $\mathrm{pH} 7.5$, at $0.010 \mathrm{~V} \mathrm{~s}^{-1}$. 
Fig. 3.

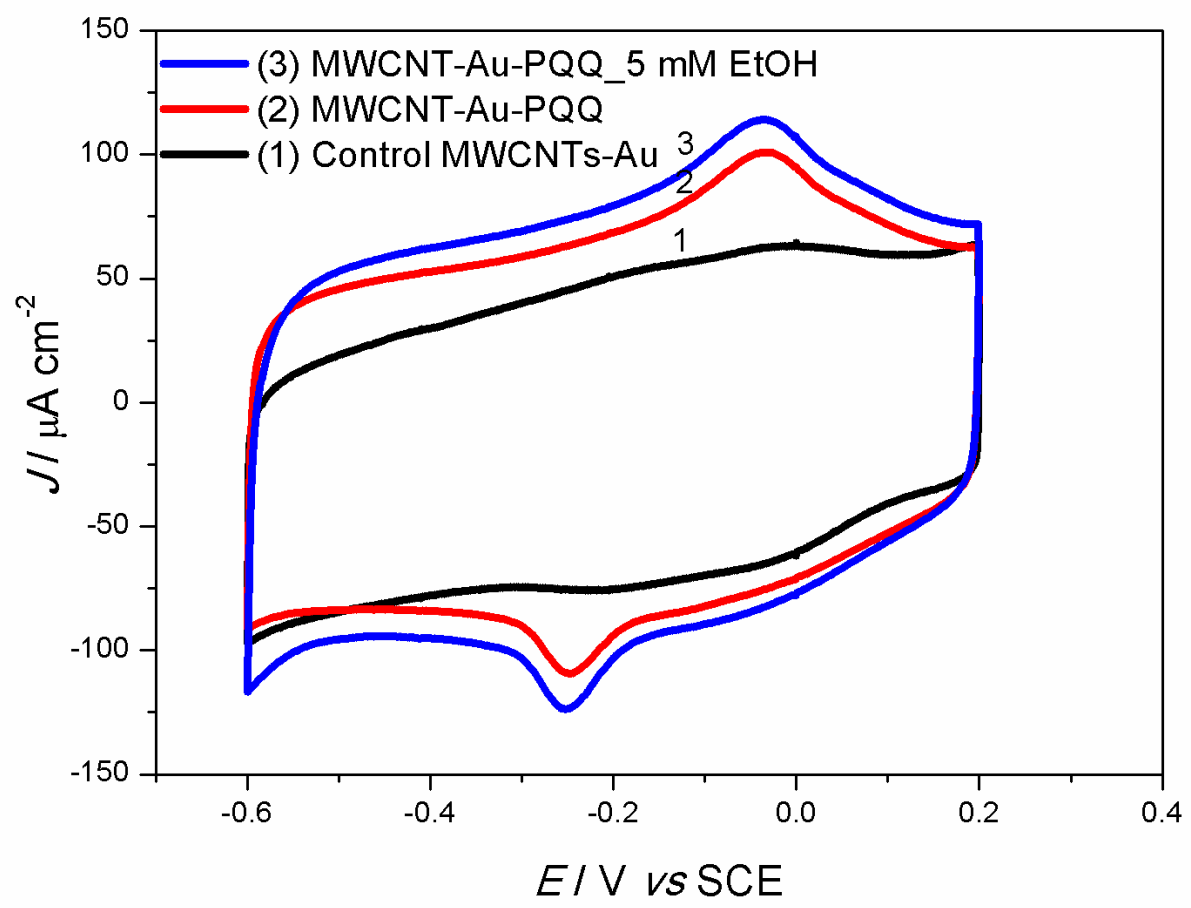

Figure 3. Representative cyclic voltammograms of the bioanodes containing both PQQ-dependent enzymes (ADH and AldDH) in DET architectures along with the Au nanoparticles modified nanotubes (MWCNTs-Au) and TBAB-modified Nafion. 0.2 mol L ${ }^{-1}$ tris $^{+}$buffer $\mathrm{pH} 7.5$, at $0.010 \mathrm{~V} \mathrm{~s}^{-1}$. 


\section{Fig. 4.}
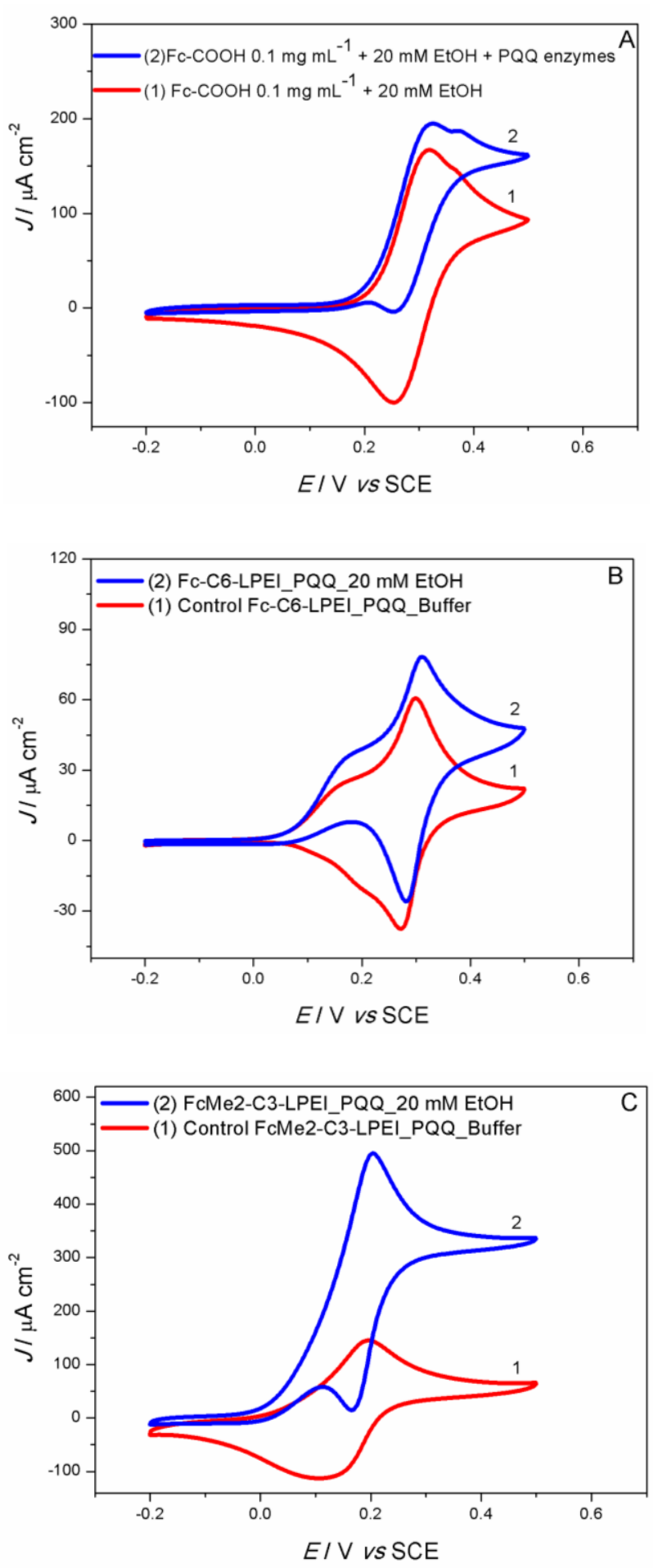

Figure 4. Representative cyclic voltammograms of (A) ferrocenecarboxylic acid $0.1 \mathrm{mg} \mathrm{mL}^{-1}$ registered in the absence and in the presence of PQQ-dependent ADH and AldDH; (B) Bioanode based on Fc-C 6 -LPEI; (C) Bioanode based on $\mathrm{FcMe}_{2}-\mathrm{C}_{3}$-LPEI. $0.2 \mathrm{~mol} \mathrm{~L}^{-1}$ phosphate buffer $\mathrm{pH} 7.5,20 \mathrm{mM}$ ethanol, at $0.010 \mathrm{~V} \mathrm{~s}^{-1}$. 
Fig. 5.
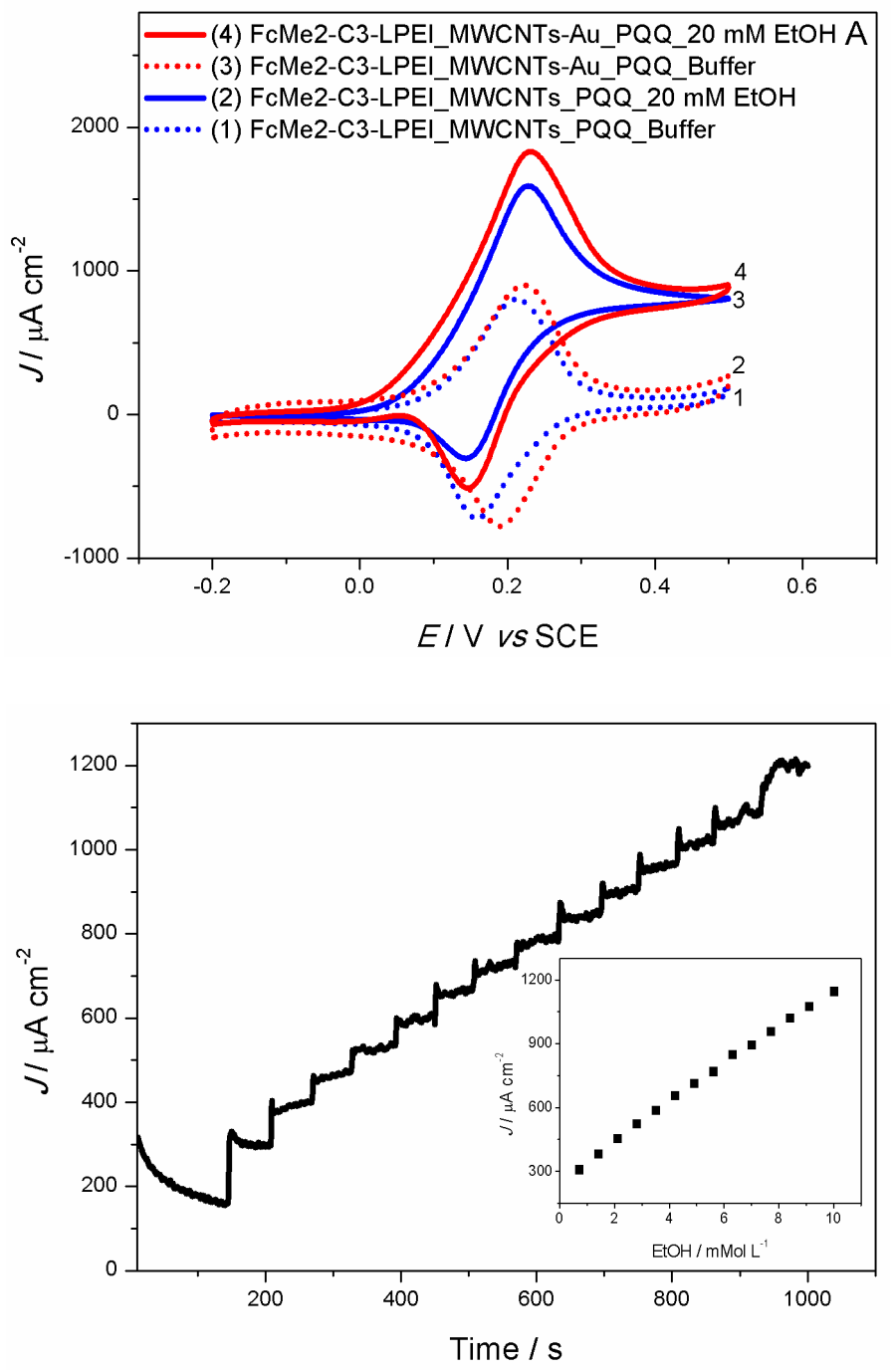

Figure 5. (A) Representative cyclic voltammograms of the bioanodes based on $\mathrm{FcMe}_{2}-\mathrm{C}_{3}$-LPEI prepared with MWCNTs or MWCNTs-Au in the absence and in the presence of $20 \mathrm{mM}$ ethanol. (B) Chronoamperometric assay performed with a bioanode prepared with the $\mathrm{FcMe}_{2}-\mathrm{C}_{3}$-LPEI redox polymer in the presence of MWCNTs-Au at a fixed oxidation potential $(0.05 \mathrm{~V}$ larger than the oxidation peak potential) by gradually increasing the concentration of substrate in the electrolyte solution. $0.2 \mathrm{~mol} \mathrm{~L}^{-1}$ phosphate buffer $\mathrm{pH} 7.5$, at $0.010 \mathrm{~V} \mathrm{~s}^{-1}$. 
Fig. 6.

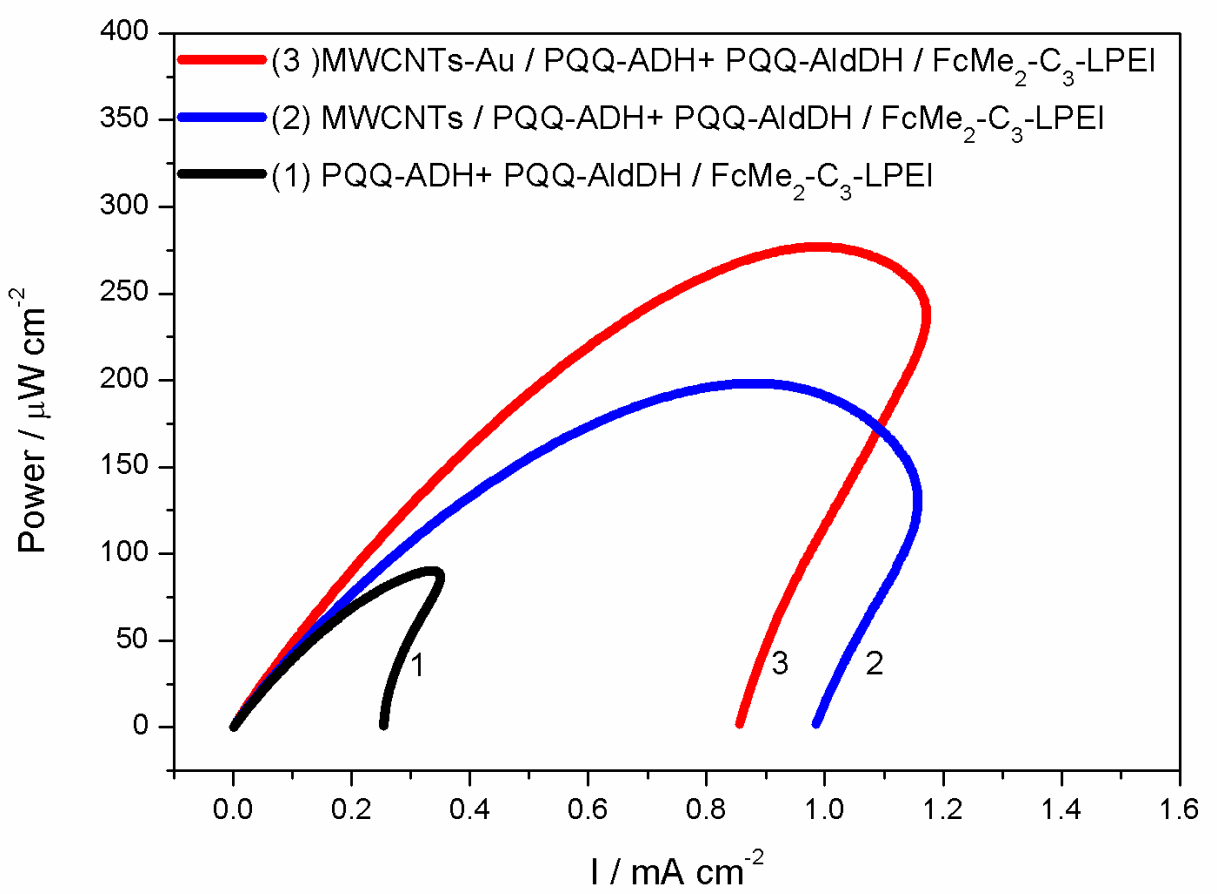

Figure 6. Representative power density curves obtained in ethanol/ $\mathrm{O}_{2}$ biofuel cell tests employing the nanostructured bioanodes prepared with the $\mathrm{FcMe}_{2}-\mathrm{C}_{3}$-LPEI redox polymer in the presence of either MWCNTs or MWCNT-decorated Au nanoparticles. The tests were performed in $0.2 \mathrm{~mol} \mathrm{~L}^{-1}$ phosphate buffer $\mathrm{pH} 7.5,0.1 \mathrm{~mol}$ $\mathrm{L}^{-1}$ sodium nitrate, and $0.02 \mathrm{~mol} \mathrm{~L}^{-1}$ ethanol at a scan rate of $1 \mathrm{mV} \mathrm{s}^{-1}$. 


\section{REFERENCES}

Aquino Neto, S., Almeida, T.S., Belnap, D.M., Minteer, S.D., De Andrade, A.R., 2015a. J. Power Sources 273, 1065-1072.

Aquino Neto, S., Almeida, T.S., Palma, L.M., Minteer, S.D., de Andrade, A.R., 2014. J. Power Sources 259, 25-32.

Aquino Neto, S., De Andrade, A.R., 2013. J. Braz. Chem. Soc. 24, 1891-1912.

Aquino Neto, S., Milton, R.D., Crepaldi, L.B., Hickey, D.P., De Andrade, A.R., Minteer, S.D., 2015b. J. Power Sources 285, 493-498.

Aquino Neto, S., Suda, E.L., Xu, S., Meredith, M.T., De Andrade, A.R., Minteer, S.D., 2013. Electrochim. Acta 87, 323-329.

Babanova, S., Matanovic, I., Atanassov, P., 2014. ChemElectroChem 1, 2017-2028.

Bullen, R.A., Arnot, T.C., Lakeman, J.B., Walsh, F.C., 2006. Biosens. Bioelectron. 21, 2015-2045.

E. Ferapontova, E., Gorton, L., 2005. Bioelectrochemistry 66, 55-63.

Falk, M., Blum, Z., Shleev, S., 2012. Electrochim. Acta 82, 191-202.

Frébortova, J., Matsushita, K., Arata, H., Adachi, O., 1998. Biochimica et Biophysica Acta (BBA) - Bioenergetics 1363, 24-34.

Giroud, F., Milton, R.D., Tan, B.-X., Minteer, S.D., 2015. ACS Catalysis 5, 1240-1244.

Gómez-Manzo, S., Escamilla, J., González-Valdez, A., López-Velázquez, G., Vanoye-

Carlo, A., Marcial-Quino, J., de la Mora-de la Mora, I., Garcia-Torres, I., Enríquez-

Flores, S., Contreras-Zentella, M., Arreguín-Espinosa, R., Kroneck, P., Sosa-Torres, M., 2015. International Journal of Molecular Sciences 16, 1293-1311.

Heller, A., 1990. Acc. Chem. Res. 23, 128-134.

Heller, A., 2004. PCCP 6, 209-216.

Hickey, D.P., Halmes, A.J., Schmidtke, D.W., Glatzhofer, D.T., 2014. Electrochim. Acta 149, 252-257.

Holland, J.T., Lau, C., Brozik, S., Atanassov, P., Banta, S., 2011. J. Am. Chem. Soc. 133, 19262-19265.

Ikeda, T., Kobayashi, D., Matsushita, F., Sagara, T., Niki, K., 1993. J. Electroanal. Chem. 361, 221-228.

Ivnitski, D., Atanassov, P., Apblett, C., 2007. Electroanalysis 19, 1562-1568.

Kavanagh, P., Leech, D., 2013. PCCP 15, 4859-4869.

Lapenaite, I., Kurtinaitiene, B., Razumiene, J., Laurinavicius, V., Marcinkeviciene, L., Bachmatova, I., Meskys, R., Ramanavicius, A., 2005. Anal. Chim. Acta 549, 140-150.

Matsushita, K., Toyama, H., Yamada, M., Adachi, O., 2002. Appl. Microbiol. Biotechnol. 58, 13-22.

Meredith, M.T., Hickey, D.P., Redemann, J.P., Schmidtke, D.W., Glatzhofer, D.T., 2013. Electrochim. Acta 92, 226-235.

Meredith, M.T., Kao, D.-Y., Hickey, D., Schmidtke, D.W., Glatzhofer, D.T., 2011. J. Electrochem. Soc. 158, B166-B174.

Meredith, M.T., Minteer, S.D., 2012. Annu. Rev. Anal. Chem. 5, 157-179.

Moehlenbrock, M.J., Meredith, M.T., Minteer, S.D., 2011. MRS Communications 1, 37-40.

Ramanavicius, A., Ramanaviciene, A., 2009. Fuel Cells 9, 25-36.

Razumiene, J., Gurevičiene, V., Vilkanauskyte, A., Marcinkevičiene, L., Bachmatova, I., Meškys, R., Laurinavičius, V., 2003. Sensors Actuators B: Chem. 95, 378-383.

Razumiene, J., Vilkanauskyte, A., Gureviciene, V., Barkauskas, J., Meskys, R., Laurinavicius, V., 2006. Electrochim. Acta 51, 5150-5156. 
Rubenwolf, S., Kerzenmacher, S., Zengerle, R., von Stetten, F., 2011. Appl. Microbiol. Biotechnol. 89, 1315-1322.

Sarma, A.K., Vatsyayan, P., Goswami, P., Minteer, S.D., 2009. Biosens. Bioelectron. 24, 2313-2322.

Schubart, I.W., Göbel, G., Lisdat, F., 2012. Electrochim. Acta 82, 224-232.

Scott, R.W.J., Wilson, O.M., Crooks, R.M., 2004. The Journal of Physical Chemistry B 109, 692-704.

Takeda, K., Matsumura, H., Ishida, T., Samejima, M., Igarashi, K., Nakamura, N., Ohno, H., 2013. Bioelectrochemistry 94, 75-78.

Tanne, C., Göbel, G., Lisdat, F., 2010. Biosens. Bioelectron. 26, 530-535.

Thomas, T.J., Ponnusamy, K.E., Chang, N.M., Galmore, K., Minteer, S.D., 2003. J. Membr. Sci. 213, 55-66.

Treu, B.L., Arechederra, R., Minteer, S.D., 2009. J. Nanosci. Nanotechnol. 9, 23742380.

Treu, B.L., Minteer, S.D., 2008. Bioelectrochemistry 74, 73-77.

Wang, X., Falk, M., Ortiz, R., Matsumura, H., Bobacka, J., Ludwig, R., Bergelin, M., Gorton, L., Shleev, S., 2012. Biosens. Bioelectron. 31, 219-225.

Wu, X., Zhao, F., Varcoe, J.R., Thumser, A.E., Avignone-Rossa, C., Slade, R.C.T., 2009. Biosens. Bioelectron. 25, 326-331.

Xu, S., Minteer, S.D., 2013. ACS Catalysis 3, 1756-1763.

Yuhashi, N., Tomiyama, M., Okuda, J., Igarashi, S., Ikebukuro, K., Sode, K., 2005. Biosens. Bioelectron. 20, 2145-2150.

Graphical Abstract
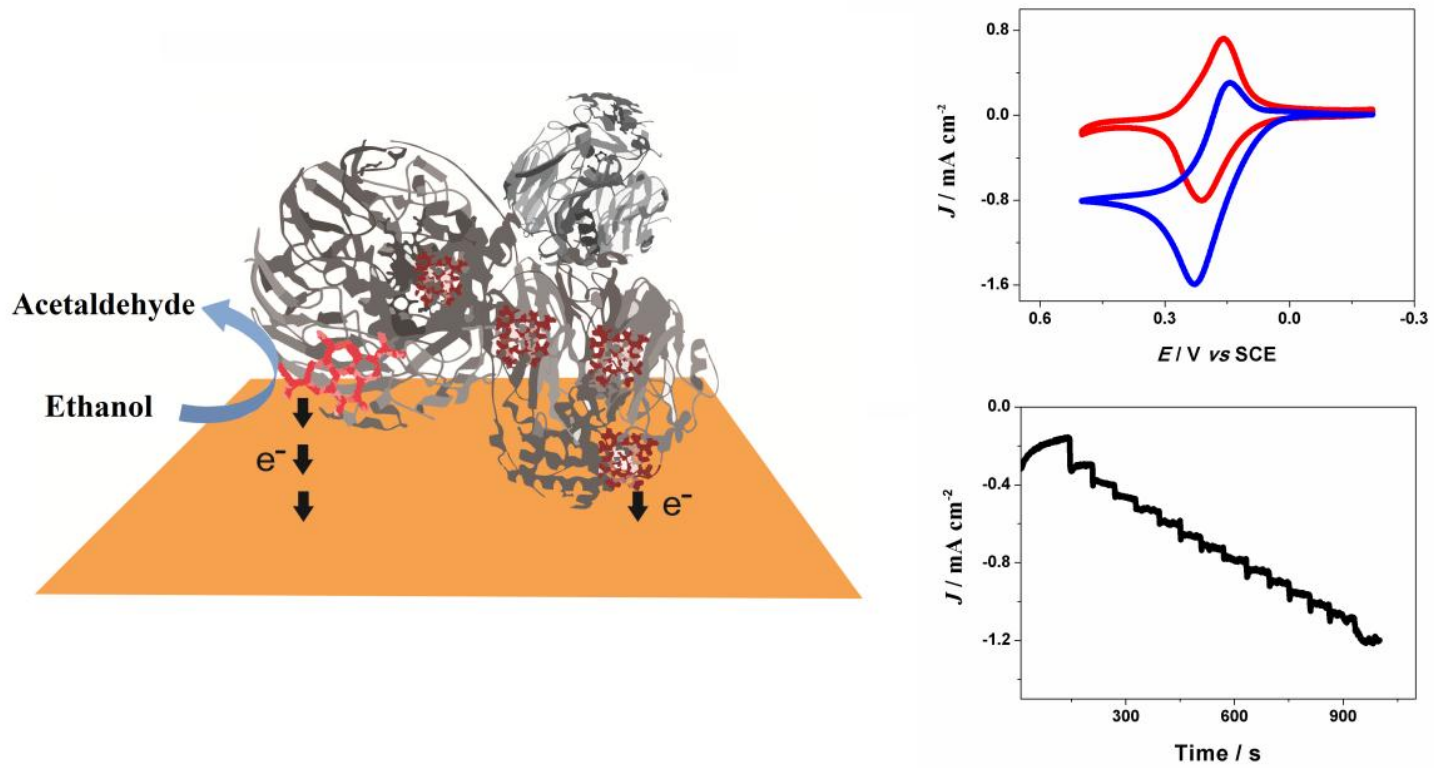